\title{
Predicting the Springback of Metal Cutting Operations Using Mesh Free Methods
}

\section{Conference Paper}

\section{Author(s):}

Imayasu, Shinya; Röthlin, Matthias; Akbari, Mansur (D); Schaal, Nikolas; Wegener, Konrad

Publication date:

2015

Permanent link:

https://doi.org/10.3929/ethz-a-010543495

Rights / license:

In Copyright - Non-Commercial Use Permitted 


\title{
Predicting the Springback of Metal Cutting Operations Using Mesh Free Methods
}

\author{
Shinya IMAYASU ${ }^{1}$, Matthias RÖTHLIN ${ }^{2}$, Mansur AKBARI ${ }^{2}$, Nikolas SCHAAL $^{2}$, Konrad WEGENER $^{2}$ \\ ${ }^{1}$ Department of Micro Engineering, Kyoto University, Japan, imayasu.shinya.72u@ st.kyoto-u.ac.jp \\ ${ }^{2}$ Institute of Machine Tools and Manufacturing, ETH Zurich, Switzerland \\ roethlin@iwf.mavt.ethz.ch, akbari@iwf.mavt.ethz.ch, schaal@iwf.mavt.ethz.ch,wegener@iwf.mavt.ethz.ch
}

\begin{abstract}
:
The metal cutting process remains one of the most widely used methods in manufacturing. Computer simulations of metal cutting are a valuable tool to understand the physics involved and to predict the outcome of such processes. One of the most important results of such simulations is the prediction of process forces. However, there is a general trend of the normal forces being underreported, independent of the numerical method chosen. Supposed factors which affect the normal forces are the material compression underneath the rounded cutting tool edge and the springback accompanied by the compression. The focus of this work is thus to simulate the process forces and the springback employing mesh free methods. The results are verified using experimental data. Predicted process forces and springback show good agreement with the experimental data.
\end{abstract}

Keywords: SPH; Springback; Metal cutting;

\section{Introduction}

Computer simulation of metal cutting operations is an active area of research. The Lagrangian Finite Element Method (FEM) has been the predominant numerical method for cutting simulations so far. However, Lagrangian mesh based methods have problems representing large deformations because mesh distortion leads to reduction of accuracy. In order to prevent mesh distortion, adaptive remeshing is commonly used in cutting simulations [1-2]. The extremely large deformations encountered in metal cutting operations entail frequent remeshing at high numerical cost.

On the other hand, mesh free methods are not limited in the deformations they can reproduce. Smoothed Particle Hydrodynamics (SPH) is one of the well-established mesh free methods which is originally developed in [3] and [4].

The SPH was first used in metal cutting simulation in [5], using the LSDYNA software. Further work can be found in [6]. Orthogonal cutting operations with an ideally sharp cutting edge were simulated. In these works, the influence of cutting speed was not discussed. In experimental works [7-8] however, it was reported that the cutting edge radius does have a considerable influence on ploughing forces. Based on that, simulations considering the influence of cutting edge radius were carried out in [9]. Meanwhile, the effect of cutting speed on process forces was investigated in [10], however the normal forces were not reported. Regarding three dimensional cutting simulations, there are few works because of high computational cost, some of which can be found in [11-12].

One of the challenges of cutting simulations is to predict process forces correctly, which consist of three components shown in Fig.1 in turning operations. However, the normal forces are generally underreported. Explanations include insufficient springback prediction of the workpiece material under the tool or insufficient contact modeling [9].

The springback in cutting operations is the elastic recovery of the workpiece compressed by the rounded cutting edge of the tool. An empirical model of process forces, taking into account the material compression related with springback, is developed in [13]. In this model, it's considered that the springback has a great influence on the normal force. Experimental work also shows that the springback follows the same trend as the normal force against the change of cutting speed in [14].

Apart from normal force prediction, the springback clearly influences the surface produced. The importance of analyzing and predicting the springback are thus twofold: Understanding the systematic underestimation of normal forces and designing highly accurate and efficient processes.

Predicting the springback is difficult because it can only be observed two orders of magnitude below the size of the cutting depth. Hence, the relationship between the springback and the normal force has not been resolved yet. Only few developments for simulating the springback of cutting processes by using FEM can be found in [2], but validation by experiment has not been done in the paper and it still remains unclear whether the relationship between the springback and the normal force with various cutting speeds can be predicted precisely or not.

In this work, the springback is predicted using a mesh free simulation method (SPH) in a 3D model, at various cutting speeds. The results are verified using experimental data.

\section{Cutting Experiment}

\subsection{Longitudinal Turning Test}

The experimental setup for the exploration of springback is described in [14]. The springback was measured in a longitudinal turning process with high cutting speed, and the overview of the process is depicted in Fig.1 (a). Meanwhile, the process forces defined in Fig.1 (b) were measured as well. The cutting conditions are summarized in Table 1.

\subsection{Measurement Equipment}

The springback is measured with capacitive type displacement sensors from Lion Precision Type C-7 C, which 
(a)

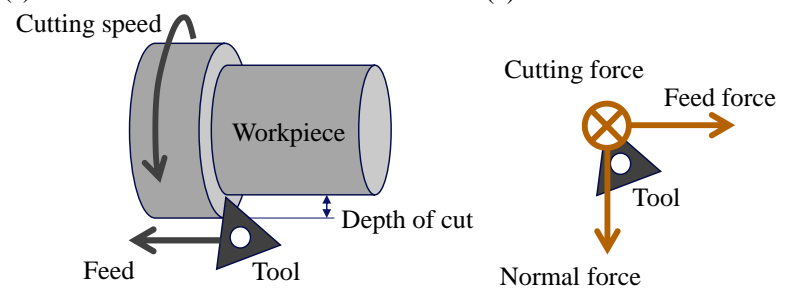

Fig. 1: Overview of (a) longitudinal cutting, (b) process forces

Table 1: Experimental cutting conditions

\begin{tabular}{c|l|l}
\hline \multirow{4}{*}{$\begin{array}{c}\text { Cutting } \\
\text { setup }\end{array}$} & Depth of cut $[\mathrm{mm}]$ & 0.05 \\
\cline { 2 - 3 } & Cutting speed $[\mathrm{m} / \mathrm{min}]$ & $150,300,450$ \\
\cline { 2 - 3 } & Feed $[\mathrm{mm} / \mathrm{rev}]$ & 0.1 \\
\hline \multirow{4}{*}{ Tool } & Material & $\begin{array}{l}\text { Tungsten } \\
\text { Carbide }\end{array}$ \\
\cline { 2 - 3 } & Nose radius $[\mathrm{mm}]$ & 0.8 \\
\cline { 2 - 3 } & Clearance angle $\left[{ }^{\circ}\right]$ & 7 \\
\cline { 2 - 3 } & Rake angle $\left[{ }^{\circ}\right]$ & 15 \\
\cline { 2 - 3 } & Cutting edge radius $[\mu \mathrm{m}]$ & 72 \\
\cline { 2 - 3 } & Side cutting edge angle $\left[{ }^{\circ}\right]$ & 5 \\
\cline { 2 - 3 } & Front cutting edge angle $\left[{ }^{\circ}\right]$ & 5 \\
\hline \multirow{4}{*}{$\begin{array}{l}\text { Work } \\
\text { piece }\end{array}$} & Material & EN-AW \\
\hline
\end{tabular}

have a measuring range of $250 \mu \mathrm{m}$ and resolution better than $10 \mathrm{~nm}$. Process forces are measured with a Kistler dynamometer of type 9121 . The measurement procedure of the springback is described in detail in [14]. The measurement uncertainty of the setup is reported as $0.85 \mu \mathrm{m}$.

\section{Simulation Model}

3D thermo-mechanically coupled numerical model of dry turning operations are made using the commercial software LSDYNA® (version R7.0.0). The tool is modeled using an FEM mesh and the workpiece is modeled with SPH particles in order to define Coulomb friction.

\subsection{Simulation Model and Boundary Conditions}

The turning operation at hand is simplified and modeled to decrease computational cost. The simulation model is depicted in Fig. 3. In the simulation, the workpiece is assumed flat and fixed in space. It is then cut by the tool model which has constant velocity in the cutting and the feed direction.

Fig. 2 shows the 3D CAD model of the tool edge based on Table 1. The tool is considered rigid in the simulations and it is discretized into FE-elements. The workpiece is discretized equally into a set of SPH particles with a particle resolution of $10^{6}$ particles $/ \mathrm{mm}^{3}$. The workpiece model has a rectangular shape with height of $0.45 \mathrm{~mm}$, width of $1.6 \mathrm{~mm}$, length of 1 $\mathrm{mm}$. Those lengths were carefully chosen to be large enough to get approximately uniformly distributed stresses on the

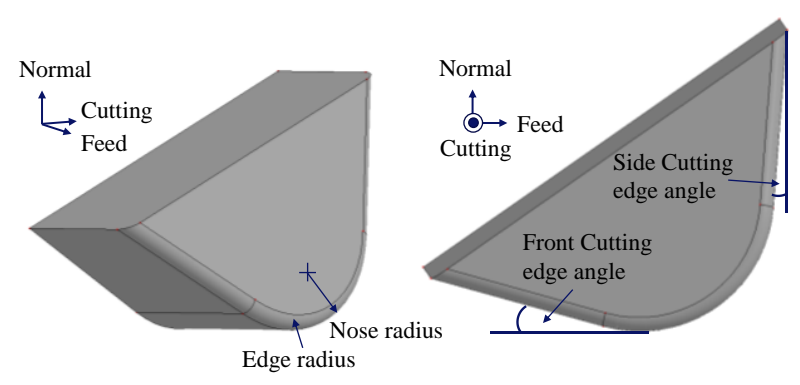

Fig. 2: 3D CAD model of the tool

boundaries as to represent an infinite half space.

The displacements are set to zero in all directions on the bottom and back surface (to ensure clean growth of the chip as the tool approaches the back surface) in accordance to Fig.3. In addition to that, the displacement of particles on the side surfaces is set to zero in the feed direction. Thermal boundary conditions are defined to keep the bottom surface and the back surface of the workpiece at $300 \mathrm{~K}$ during the simulation. Initial temperature of all elements is $300 \mathrm{~K}$ as well. Heat transfer between the tool and the workpiece is not considered. It is supposed that the influence of heat transfer between the tool and the workpiece is quite small because the amount of heat transferred into the tool reduces significantly with increasing cutting speed.

Contact between the tool model and the workpiece model is established using a node-to-surface contact algorithm. Coulomb friction with upper limit is adopted as the friction model on the interface between the tool and the workpiece. The friction coefficient was fit by the following procedure: The friction parameter was varied in the range from 0.1 to 1 at the highest cutting speed $(450 \mathrm{~m} / \mathrm{min})$ and chosen such that the error to the experimental values at this speed is minimized. The resulting friction parameter was then used for all other simulations. The upper limit of friction forces is set to the shear yield stress of the workpiece material.

The cutting area is important for predicting process forces. Hence, the two tool paths were simulated to match the cutting area of the experiment. The two tool paths are shown in Fig. 4 (Top view of Fig. 3). The tool model cuts the workpiece model on the first tool path with constant cutting and feed speed. After that, the tool model jumps back to the start point of the second tool path, i.e. the feed distance for one revolution away in feed direction from the start point of the first tool path. The second cut is then carried out.

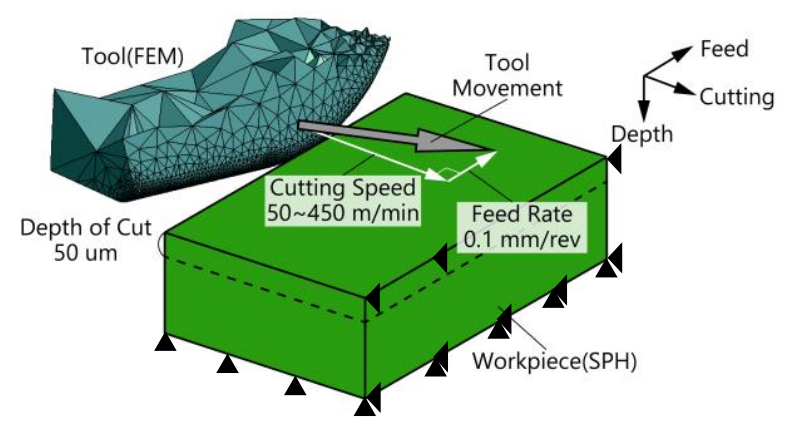

Fig. 3: Simulation model 


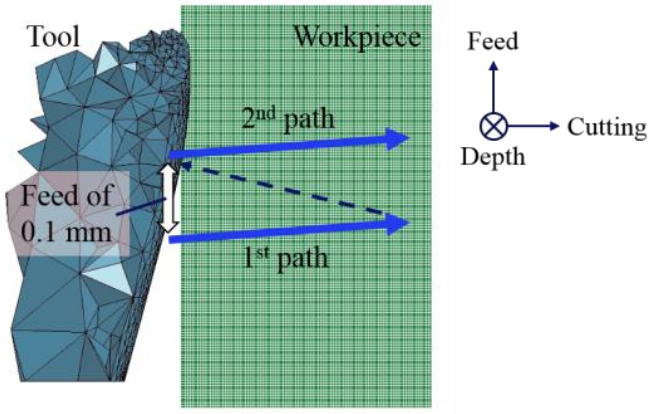

Fig. 4: Two tool paths for process forces simulation

The process forces of the second tool path are used for validation with the experimental data concerning the process forces. As for the springback, however, the cutting grove of the first tool path was used on the assumption that the influence of the cutting area on the springback is small.

\subsection{Material Modeling}

The workpiece is considered elasto-plastic. Cutting speed and cutting heat are important factors in cutting operations, thus the Johnson-Cook constitutive equation is used for plastic behavior of the workpiece, in which flow stress is related not only with strain but strain rate and temperature as well [15]:

$$
\sigma=\left(A+B \varepsilon_{p}{ }^{n}\right)\left(1+C \ln \left(\frac{\dot{\dot{\varepsilon}_{p}}}{\dot{\bar{\varepsilon}}_{p 0}}\right)\right)\left(1-\left(\frac{T-T_{\text {room }}}{T_{\text {melt }}-T_{\text {room }}}\right)^{m}\right)
$$

Where $\sigma$ is the flow stress, $\varepsilon_{p}$ is the equivalent plastic strain, $\dot{\bar{\varepsilon}}$ is the equivalent plastic strain rate, $\dot{\bar{\varepsilon}}_{p 0}$ is the reference strain rate, $T$ the temperature, $T_{\text {melt }}$ the melting temperature and $T_{\text {room }}$ the room temperature. Finally, $A, B, n, C$ and $m$ are the material specific flow stress parameters. It is assumed that the Johnson-Cook model has problems representing velocity dependency of steel and alloy steel accurately, but it's reported that the model is valuable for Aluminum alloys [16]. The parameters $A, B, n$ were identified by a quasi-static tensile test in the condition of $\dot{\bar{\varepsilon}}_{p 0}$ equal to $0.02 \mathrm{~s}^{-1}$, whereas for $C, m$ literature values of EN-AW 6061A T6 are used [16]. This is based on the assumption that the influence of strain rate and temperature is similar in the same 6000 -series solution heat-

Table 2: Flow stress parameters of workpiece

\begin{tabular}{c|c|c|c|c}
\hline $\mathrm{A}[\mathrm{MPa}]$ & $\mathrm{B}[\mathrm{MPa}]$ & $\mathrm{n}$ & $\mathrm{C}$ & $\mathrm{m}$ \\
\hline 340 & 257.56 & 0.3908 & 0.011 & 1.34 \\
\hline
\end{tabular}

Table 3: Material properties of workpiece material

\begin{tabular}{l|l}
\hline Density $\left[\mathrm{g} / \mathrm{cm}^{3}\right]$ & 2.7 \\
\hline Young's modulus $[\mathrm{GPa}]$ & 70.6 \\
\hline Shear Modulus $[\mathrm{GPa}]$ & $34^{*}$ \\
\hline Poisson's Ratio & $0.33^{*}$ \\
\hline Melting temperature $[\mathrm{K}]$ & $855^{*}$ \\
\hline Specific heat $[\mathrm{J} / \mathrm{kg} \cdot \mathrm{K}]$ & $895^{*}$ \\
\hline Thermal conductivity $[\mathrm{W} / \mathrm{m} \cdot \mathrm{K}]$ & 172 \\
\hline
\end{tabular}

*: from the value of EN-AW 6061AT6

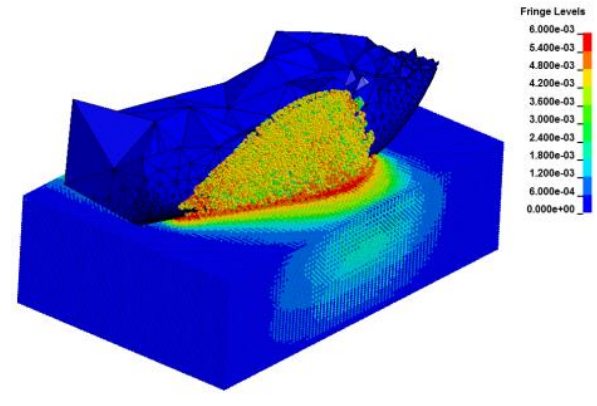

Fig. 5: Von Mises stress distribution $\left[\mathrm{g} \cdot \mathrm{cm} /\left(\mu \mathrm{s}^{2} \cdot \mathrm{cm}^{2}\right)\right]$
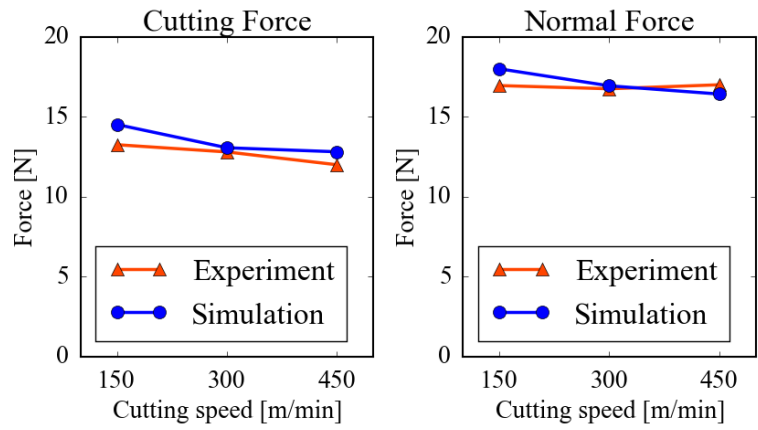

Fig. 6: Comparison of process forces between experiment and simulation

treated Aluminum alloy. Future work will address this weakness in the material modeling. The flow stress parameters used are shown in Table 2 and Table 3 shows the other material properties of the workpiece.

\section{Simulation Results}

Von Mises stress distribution with cutting speed of 450 $\mathrm{m} / \mathrm{min}$ at the first path is plotted in Fig. 5. From this simulation, the process forces and the springback are predicted.

\subsection{Process Forces}

The simulations are run until the forces reach steady state and continued for some time. The final process forces are obtained by averaging over the force history of the steady state. The simulated process forces are shown in Fig. 6 in comparison with the measured forces. The simulated process forces are in good agreement with the measured forces. Maximum prediction error is $9.5 \%$ for the cutting force and $5.9 \%$ for the normal force. This $9.5 \%$ deviation between simulation and experiment can be explained by considering the uncertainties in experimental results as explained in [17]. Compared with other works $[5,6,9]$, the results are of considerable accuracy. As mentioned, there is a general trend that the error in the prediction of the normal force is one order of magnitude larger than the error in the prediction of the cutting force. This is not observed in this case. Preliminary studies show that part of the under estimation of spring back can be attributed to insufficient numerical resolution, which was avoided in this work at the cost of increased simulation times.

\subsection{Springback}

The springback is defined as the normal distance between the tool tip and the machined surface due to elastic deformation 


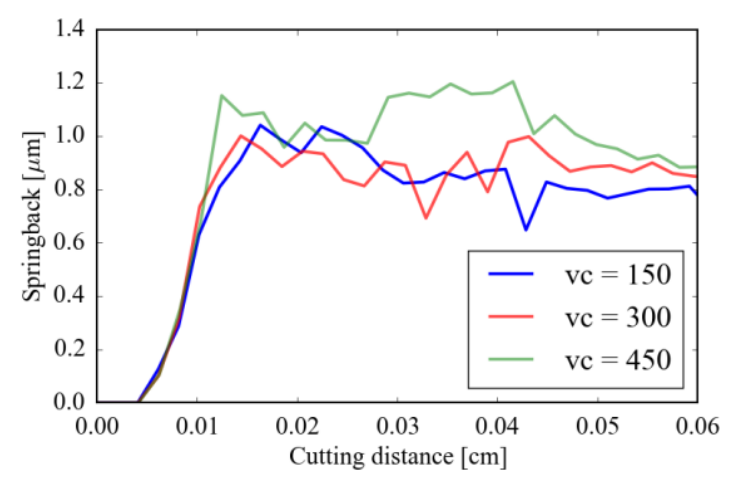

Fig. 7: Result of spring back in cutting simulation

in the experiment. Thus, in the simulation, the normal distance between the tool tip and the SPH particles located over the machined surface in the surrounding area where the tool tip passed was evaluated as the springback.

The relationship between the predicted springback and cutting distance from the start point of the first path is plotted in Fig. 7. From the figure it is evident that the predicted springback increases with increasing cutting speeds. Fig. 8 shows the comparison of average value of the springback between experiment and simulation in steady-state. The springback is underestimated in all cutting speeds. However, all springback results are within the measurement uncertainty of the measuring set-up in the experiment $(0.85 \mu \mathrm{m})$.

In addition, the SPH simulation shows the ability to reproduce the velocity dependency of the springback. The underestimation trend of the springback may be related to not using material parameters of exactly the same aluminum alloy used in the experiment and also not considering thermal change of the Young's modulus. The Johnson-Cook constitutive equation does define thermal softening of flow stress of the workpiece, but the Young's modulus is defined as a constant value regardless of the material temperature in this simulation.

\section{Conclusions}

The results are summarized as follows:

1) The process forces were simulated with considerable accuracy: A maximum error of $9.5 \%$ was observed

2) The simulated springback is underestimated but still in good agreement with the experiment considering the measurement uncertainty of the measuring set-up.

3) The simulation resolves the velocity dependency of the springback. Thus, the SPH methods can be a valuable tool to simulate the springback in cutting operations.

Future work will be expanding on these results considering different materials and cutting tools. Material parameter identification will be improved. Moreover, temperature variable Young's modulus will be investigated concerning its influence on the springback and the process forces.

\section{Reference}

[1] Ceretti, E. et al., 1999, FEM simulation of orthogonal cutting: serrated chip formation, J. Mater. Process. Technol. 95.1, pp.17-26.

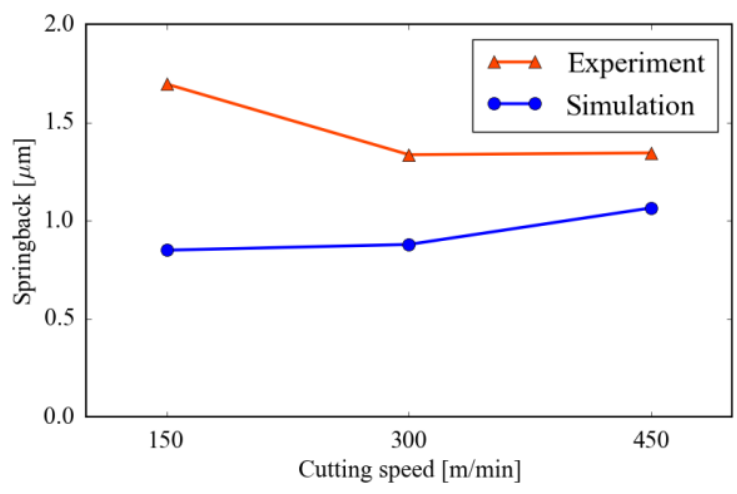

Fig.8: Comparison of the spring-back between experiment and simulation

[2] Ducobu, F. et al., 2011, A Lagrangian FEM model to produce saw-toothed macro-chip and to study the depth of cut influence on its formation in orthogonal cutting of Ti6Al4V, Adv. Mater. Res. 223, pp.3-11.

[3] Lucy, L.B., 1977, A numerical approach to the testing of the fission hypothesis, Astron. J. 82, pp.1013-1024.

[4] Gingold, R.A., Monaghan, J.J., 1977, Smoothed particle hydrodynamics: theory and application to non-spherical stars, Monthly Notices R. Astron. Soc. 181, pp.375-389.

[5] Limido, J. et al., 2006, A new approach of high speed cutting modelling, J. Phys. IV 134, pp.1195

[6] Villumsen, M.F., Fauerholdt T.G., 2008, Simulation of Metal Cutting Using Smooth Particle Hydrodynamics, LS-DYNA Anwenderforum, C-III, pp.17

[7] Waldorf, D.J. et al., 1999, An evaluation of ploughing models for orthogonal machining, J. Manuf. Sci. Eng. 121.4, pp.550-558.

[8] Wyen, C.F., 2011, Rounded cutting edges and their influence in machining titanium, $\mathrm{PhD}$ thesis, ETH Zürich

[9] Ruettimann, N., 2012, Simulation of metal cutting processes using meshfree method, $\mathrm{PhD}$ thesis, ETH Zürich

[10] Martin, M., Píška, M., 2013, On the SPH orthogonal cutting simulation of A2024-T351 alloy, Procedia CIRP 8, pp.152-157.

[11] Ruettimann, N. et al., 2013, Simulation of hexaoctahedral diamond grain cutting tests using the SPH method, Procedia CIRP 8, pp.322-327

[12] Ruettimann, N. et al., 2010, Simulation of single grain cutting using SPH method, J. Mech. Eng. 10, pp 17-29

[13] Friedrich, C.R., Kulkarni, V.P., 2004, Effect of workpiece springback on micromilling forces, Microsystem technologies 10.6-7, pp.472-477

[14] Schaal, N. et al., 2015, Springback in metal cutting with high cutting speeds, Procedia CIRP, Volume 31, pp 24-28

[15] Johnson, G.R., Cook, W.H., 1983, A constitutive model and data for metals subjected to large strains, high strain rates and high temperatures, Proc. 7th Inter. Symp. Ballistics. Vol. 21

[16] Dariani, B.M. et al., 2009, Experimental investigation of sheet metal formability under various strain rates, Proc. Inst. Mech. Eng. Part B: J. Eng. Manuf. 223.6, pp 703712.

[17] Akbari, M. et al., 2015, Comparison of Transparent Objects Metrology through Diamond Cutting Edge Radii Measurements, CIRP J. Manuf. Sci. Technol. (Submitted) 